\title{
Fundamentos éticos e morais na prática de enfermagem
}

Aceito para publicação em outubro de $\mathbf{2 0 1 0}$

Genival Fernandes de Freitas ${ }^{1}$

Taka Oguisso ${ }^{2}$

Maria de Fátima Prado Fernandes ${ }^{3}$

Este trabalho tem por objetivo refletir e analisar os fundamentos éticos e morais e sua aplicação no exercício da enfermagem: a ética na perspectiva histórica e na prática e em sua concretização no Código de Ética de Enfermagem.

Descritores: Ética e Moral, Exercício da Enfermagem, Código de Ética de Enfermagem.

\section{Ethical and moral pleas in the practice of nursing}

This paper aims at reflecting about and analyzing ethical and moral fundamentals in the nursing practice: ethics in the historical and practical perspectives, and its concretion into the Nursing Ethics Code.

Descriptors: Ethics and Moral, Nursing Practice, Nursing Ethics Code.

\section{Fundamentos éticos y morales en la practica de la enfermería}

Se trata de reflejar sobre y analizar los fundamentos éticos y morales y su aplicación en el ejercicio de la enfermería: la etica en la perspectiva historica, en la practica y su concretización en el Código de Ética de Enfermería.

Descriptores: Etica y Moral, Practica de la Enfermería, Código de Etica de la Enfermería.

\section{INTRODUÇÃO}

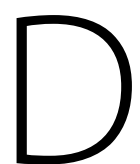
esde a antiguidade - antes de Cristo -, filósofos gregos entendiam que os princípios inspiradores chamavam-se ethos. Esse termo é sinônimo de ética, ou seja, o conjunto ordenado de princípios, valores e motivações últimas das práticas humanas, pessoais e sociais. Ética também significa o caráter ou o modo de ser de uma pessoa ou de uma comunidade. Assim, as pessoas que moram nela (nessa casa concreta, isto é, família, tribo, comunidade) têm valores, princípios e motivações inspiradoras para o comportamento.

A partir da Idade Média - com a influência do cristianismo -, usava-se a palavra moral (do latim: mos/mores), equivalente a costumes e hábitos, tanto para os costumes quanto para o caráter e os princípios e valores que moldam a conduta, o agir em sociedade ou no grupo social em que o indivíduo se encontra inserido.

A ética compreende a experiência da "morada humana", que não significa um determinado espaço físico, mas sim uma teia de relações interpessoais ou interprofissionais de onde emergem as relações entre os moradores e entre os vizinhos. Tais relações ocorrem segundo critérios de valores, crenças e visões de mundo, que se fundam em princípios ou fundamentos, para que a convivência humana aconteça da forma mais harmoniosa possível - o que não significa ausência de conflitos. Esses estão presentes na convivência humana, que se move por interesses pessoais ou grupais.

Há várias concepções éticas e morais de acordo com o contexto cultural. Pode-se falar da ética e da moral capitalistas vigentes em nossos dias. Na perspectiva capitalista, diz-se que bom é o que permite acumular mais com menos investimento e em menor tempo possível, ou seja, concentrar bens, riquezas. A moral capitalista consiste em "empregar menos gente possível, pagar menos salários e impostos e explorar melhor a natureza para acumular mais meios de vida e de riqueza"(1). Mas, no senso comum, diz-se que uma pessoa é ética quando se orienta por princípios, convicções e valores. Em outras palavras, diz-se que essa pessoa tem boa índole.

Ao contrário, quando um comportamento é considerado antiético? Expondo o paciente a uma situação de perigo, de risco à própria vida e segurança desnecessariamente. Por desídia, negligência ou mesmo imprudência, o profissional que assim se comporta estaria agindo de modo antiético ou deixando de agir (negligência), provocando situações em que danos decorrentes de sua ação possam advir ao paciente. Tal comportamento estaria contrariando, a priori, o princípio ético segundo o qual é uma deontologia (uma obrigação) "assegurar ao cliente uma assistência de enfermagem isenta de riscos decorrentes de negligência (omissão), imprudência

1 Professor-doutor do departamento de orientação profissional da Escola de Enfermagem da Universidade de São Paulo - Eeusp. Email: genivalf@usp.br.

2 Professora titular do departamento de orientação profissional da Escola de Enfermagem da Universidade de São Paulo - Eeusp.

3 Professora-doutora do departamento de orientação profissional da Escola de Enfermagem da Universidade de São Paulo - Eeusp. 
ou imperícia" (2).

Diz-se que "uma pessoa é moral quando age em conformidade com os costumes e hábitos 'consagrados' social ou culturalmente". Por exemplo, o profissional que exigir ou determinar que o paciente aceite a transfusão de sangue, contrariando ou desconsiderando suas convicções e crenças ou da coletividade a que ele pertence, poderá ser denunciado por abuso de autoridade e desrespeito à autonomia do paciente de recusar um tratamento médico. É preciso, nesses casos, considerar, entretanto, o dever do profissional de informar o paciente sobre os riscos, implicações e opções, caso não aceite o tratamento, mas jamais poderá impor sua vontade.

Em que consistem os princípios senão em alicerces, origens ou fundamentos das ações humanas ou bases para as deliberações e tomadas de decisão? Segundo Miguel Reale, princípios são "verdades fundantes de um sistema de conhecimento, como tais admitidas por serem evidentes ou por terem sido comprovadas, mas também por motivos de ordem prática de caráter operacional, isto é, como pressupostos exigidos pelas necessidades da práxis" (3).

A dimensão ética da existência humana é contemplada, ao longo da história da humanidade, por grandes filósofos. Assim, Platão dizia que "o homem é um ser político", porque vive em sociedades, nas pólis, nas cidades, nos grupos sociais, em constantes interações com outros homens.

O homem é o único ser que, ao mesmo tempo em que vê algo, também analisa, interpreta, dá significado e racionaliza. Assim, ele pensa, questiona, investiga e exprime pensamentos e ideias por palavras com certa lógica, com concatenação. É capaz de relacionar-se com o outro, com o mundo e consigo mesmo. $\mathrm{O}$ homem é, segundo Kant, o único ser que pode dispor de sua vontade; tem amor pela sabedoria; é capaz de criar, construir e transformar algo a partir da própria realidade. Sobre o homem pensador, a clássica obra de Auguste Rodin, de 1889, tornou célebre a imagem de um ser reflexivo, voltado para si mesmo, pensativo e questionador.

\section{A ÉTICA NA PERSPECTIVA HISTÓRICA: DICEOLOGIA E DEONTOLOGIA}

Breve retrospectiva histórica acerca da etimologia do termo ética revela-nos que, desde a antiguidade, os gregos entendiam a ética de duas maneiras: o termo ethos (com "e" longo), que significava morada humana, caráter, jeito ou modo de ser, perfil da pessoa; ou ethos (com "e" curto), para dizer costumes, hábitos ou comportamentos concretos das pessoas. Cabe pontuar que a morada a que faz menção o povo grego, ao se referir à ética, não deve ser compreendida do ponto de vista físico, mas existencial, ou seja, a morada seria a teia das relações sociais, o meio físico e os recursos materiais e espirituais. A morada corresponderia, na concepção existencialista, às relações humanas, sociais, entre as pessoas ${ }^{(1)}$.
A ética, como parte da filosofia, considera concepções acerca da vida, do universo, do ser humano e de seu destino; estatui princípios e valores que orientam pessoas e sociedades humanas. Ademais, a ética é um dos instrumentos de que o homem lança mão para garantir a convivência social. A ética consiste na reflexão que interpreta, discute e problematiza os valores, princípios e regras morais, uma vez que se propõe a perscrutar o que é bom e belo para a vida em sociedade ${ }^{(4)}$.

Para Murachco, a ética vem do interior da pessoa e atua de dentro para fora ${ }^{(5)}$. Outros autores consideram que a ética corresponde ao modo de ser ou caráter adquirido pelo homem $^{(6,7)}$. Assim, a ética provoca no ser uma reflexão com base em princípios e valores que orientam sua vida; reflete o pensar e o questionar a realidade circundante. Envolve valores e vem de dentro da pessoa, o que constitui um caráter individual e significa "modo de ser" ou "morada do ser", englobando consciência, conhecimento, concepção, liberdade e responsabilidade.

O profissional de saúde deve perceber os conflitos éticos e ter consciência deles. Além disso, deve saber e poder posicionar-se com autonomia face à existência desses conflitos e realizar escolhas coerentes, tendo em vista os princípios éticos de sua profissão ${ }^{(8)}$.

Entretanto, a simples existência de códigos de ética não torna as relações mais ou menos éticas, pois essas normatizações assinalam apenas os valores que uma determinada coletividade considera como sendo necessários para que cada membro possa interagir e trabalhar.

Ademais, os códigos de ética devem ajustar-se, continuamente, às situações novas que as transformações sociais e científicas suscitam a cada momento. Essas envolvem temáticas como a manutenção artificial de certas funções vitais e transplantes de órgãos, entre diversos aspectos tão comuns nos dias de hoje, graças aos avanços tecnológicos e suas implicações éticas na área da saúde.

A ética considera concepções de fundo acerca da vida, do universo, do ser humano e de seu destino, estatuindo princípios e valores que devem orientar pessoas e grupos. Diz-se que uma pessoa é ética quando se orienta por princípios e convicções e é moral quando age conforme costumes e valores consagrados. Assim, a moral, na opinião desse autor, é parte da vida concreta e trata da prática real das pessoas que se expressam por costumes, hábitos e valores culturalmente estabelecidos. A moral consiste em um conjunto de normas ou regras admitidas em uma determinada época por um grupo de pessoas e que norteiam o comportamento humano(1).

Os códigos, em geral, mostram os valores que a cultura de uma determinada sociedade considera necessários para que seu membro possa interagir. Nessa perspectiva, a ética referese a algo que emerge das emoções e da razão de cada pessoa, tendo como pressuposto a autonomia. A moral, por outro lado, consiste no conjunto de direitos e deveres impostos durante a 
estruturação da personalidade e ao longo de toda a vida ${ }^{(9)}$.

A moral reflete costumes, regras e deveres/valores que vêm de dentro da sociedade. Sendo assim, a moral possui um caráter coletivo, um modo de ser da sociedade, do grupo social. Ela engloba diversos aspectos: históricos, culturais, educativos, políticos, em relação ao poder, à consciência eà responsabilidade, bem como a prática da liberdade e autonomia ${ }^{(6,7)}$.

A moral se define pela necessidade de o homem instituir regras de como deve conviver, que, por sua vez, provêm da sociedade. Muitas vezes, o que é aceito em uma determinada sociedade pode não ser em outra, porque há mores diferentes, cultura e valores específicos de cada uma.

O sentido do ser reflete o "eu" que existe na pessoa, como se relaciona consigo mesma, com os outros e com o mundo. Assim, na construção do ser ético, o modo de pensar reflete no modo de agir, de viver e de relacionar-se com as demais pessoas $^{(8)}$.

A eticidade engloba a condição para ser ético, a aptidão de exercer a ação de modo ético e o modo de ser, ou seja, como a pessoa constrói a vida a partir de si mesma nas relações interpessoais e na relação com o mundo(4).

\section{A ÉTICA NA PERSPECTIVA DA PRÁTICA PROFISSIONAL}

Ao pensarmos sobre os fundamentos ou princípios éticos que pautam a ação do enfermeiro, não podemos negligenciar as questões sobre as quais estamos discorrendo. Pois o exercício da enfermagem engloba, basicamente, consciência, liberdade, valores e responsabilidades, que se encontram inseridos no contexto culturalmente construído ou transformado de nossos tempos, como significados atribuídos socialmente ao fazer do enfermeiro.

Nessa direção, cabe ressaltar a concepção de cultura, como um acervo do saber que os participantes (os atores sociais) produzem, sendo a comunicação um processo fundamental para possibilitar as interpretações sobre a realidade de algo no mundo. Assim, a cultura histórica sobre o processo saúdedoença, por exemplo, seria resultado das interpretações que as ditas situações produzem em uma determinada sociedade através dos tempos.

Outro fundamento da ação profissional são os valores que ajudam as pessoas a tomarem decisões, possibilitando a eleição de um caminho, de uma direção determinada, assumindo um posicionamento a partir de suas escolhas. Os valores que atribuímos às coisas e aos objetos se entendem como aquilo que fazemos valer, dando juízo de valor. Assim, os valores são como forças propulsoras, pois impulsionam as ações humanas. Um indivíduo sem valores perderia o sentido da vida e se alienaria. Os valores são normas, princípios e padrões socialmente aceitos pelo indivíduo, classe ou sociedade, pelos quais uma determinada pessoa é estimável em maior ou menor $\operatorname{grau}^{(7)}$.

Ao considerarmos a dimensão ética do agir do enfermeiro, é preciso pensar na questão da heteronomia e da autonomia. A primeira aceita a norma externa, por conformismo ou coerção (desse modo, a lei é considerada a principal fonte do direito positivista e se impõe de modo coercitivo, independentemente das vontades individuais). Por outro ângulo, na autonomia, não se nega a influência externa das normas postas nem das regras jurídicas, porém há um espaço de reflexão sobre as próprias contingências e limitações das normas.

A liberdade, como elemento fundamental da ação humana e, particularmente, da ação profissional, engloba a diversidade e as possibilidades. É possível que a liberdade consista na capacidade do indivíduo de dominar e superar obstáculos. Ser livre é também ser e o poder ser, no sentido de realizar suas potencialidades. Diz-se que a liberdade de cada um encontra limites na liberdade do outro e que não há responsabilidade sem liberdade ou viceversa(10) $^{(10}$

A liberdade é condição fundamental para a compreensão da abrangência e o significado da responsabilidade, pois se considera que um indivíduo é plenamente responsável quando é capaz de escolher, de optar, sem coação de qualquer natureza. Assim, a liberdade encontra-se no bojo das relações ou das manifestações de autonomia do indivíduo. A autonomia, desse modo, quer dizer o direito de dirigir-se, de governar-se e de escolher ${ }^{(10)}$.

Nessa perspectiva, a liberdade representa a possibilidade de traçar caminhos, propor soluções e opções e superar limites. Assim, o limite é bom, pois é a partir dele que o homem faz escolhas mais conscientes. A liberdade associa-se à escolha e é sempre um projeto possível de realização quando o indivíduo tem condições de escolher com consciência, conhecimento e sabedoria, fundamentando sua decisão. Ao decidir, aprende-se a optar. Esse movimento faz parte do aprendizado e consiste em assumir as consequências do agir, as injunções e interferências das decisões, o que faz parte do processo para aprender a ser responsável(11).

A liberdade consiste em um fundamento ético do agir e se constitui em alicerce para a tomada de decisão autônoma dos indivíduos. Assim, no tocante à pesquisa com seres humanos, por exemplo, cabe ressaltar o pensamento de José Roberto Goldim, que propugna que a autonomia envolve a tomada de decisão livre e responsável, incorporando, pelo menos, duas convicções éticas: os indivíduos devem ser tratados como agentes autônomos e as pessoas com autonomia diminuída devem ser protegidas. Dessa forma, há exigências morais distintas: a exigência do reconhecimento da autonomia e a exigência de proteger aqueles com autonomia reduzida ${ }^{(12)}$.

Agir de forma consciente requer uma percepção de si, do meio e dos outros, envolvendo também sabedoria, razão, comunicação/interação, concepções, valores e cultura, além da 
vontade, ou seja, do querer e do propiciar abertura para o outro. Assim, a consciência constitui-se em outro fundamento da ação profissional, porque integra o processo de tomada de decisão, que está na contingência cotidiana do trabalho do enfermeiro.

Ser responsável engloba, além da liberdade de opção ou ação, a consciência de poder agir e escolher com capacidade, com vontade e discernimento entre duas ou mais possibilidades. Desse modo, só é plenamente responsável quem é capaz de agir com liberdade e com ciência dos desdobramentos de sua ação, ou seja, o agir responsável pauta-se nos valores pessoais e do grupo social. Nesse sentido, a vontade está ligada à potência, ou seja, o indivíduo se vê quando pode visualizar as possibilidades que o mundo the traz, que surgem diante de si e que podem se tornar realidade. A vontade é parcial ou totalmente determinada pelo social, incluindo crenças e valores, pois o desejo é tocado por algo que já existe na sociedade ${ }^{(4)}$.

A responsabilidade profissional consiste na perspectiva dos fundamentos éticos da ação e no ato de responder pelos próprios atos ou pelos de outrem, sempre que esses resultem em prejuízo a terceiros ${ }^{(13,14)}$. Por outro lado, a responsabilidade consiste no fato de poder estar em condições de tornar-se responsável por algo ou alguém(11).

Os fundamentos éticos da ação do enfermeiro (como gerente ou educador e ao prestar o cuidado direto ao paciente) devem pautar toda a sua ação, auxiliando-o no discernimento e na escolha. Diante de contingências cotidianas, com base nos valores profissionais e na consciência dos direitos e dos deveres profissionais (deontologia e diceologia), bem como a partir da percepção da realidade que vivencia, o enfermeiro age e decide como e quando fazer algo. Portanto, seu processo decisório não se limita às normas (muitas vezes cristalizadas ou inflexíveis) dos códigos de conduta profissional, sendo ele capaz de refletir de forma responsável e consciente, optando com liberdade sobre qual a melhor possibilidade de ação e partindo de sua bagagem de conhecimentos à mão, produto da experiência de vida acumulada e compartilhada com os semelhantes.

Portanto, vimos que os fundamentos do agir se pautam nas concepções de vida, valores, crenças, desejos, motivações, intencionalidades, necessidades e possibilidades, perpassando o diálogo aberto, crítico, reflexivo e consensual. Ao agir de modo ético, o enfermeiro repensa a responsabilidade individual e institucional, englobando as relações do mundo do trabalho (os recursos humanos e materiais de que dispõe), avaliando e transformando as condições de trabalho e modificando as relações, a fim de garantir uma assistência de enfermagem segura à clientela por ele assistida, com isenção de riscos e propiciando maiores benefícios possíveis.

\section{A CONCRETIZAÇÃO DOS FUNDAMENTOS ÉTICOS E MORAIS NO CEPE}

A ação do enfermeiro não se pauta, unicamente, na competência do saber fazer, englobando outras dimensões igualmente relevantes, como o saber conviver e saber ser, relacionar-se e comunicar-se com os demais. Assim, faz-se necessário ponderarmos que a cultura provém do modo de agir, das inovações, das transformações daquilo que se interpreta, até produzir um novo jeito de ser, liberando-se das rígidas determinações preestabelecidas pelos códigos, pela sociedade.

Com isso, o pensamento ético propulsiona a avaliação das atribuições ou ações profissionais da enfermagem, englobando as competências (privativas e exclusivas) do enfermeiro. $\mathrm{O}$ Código de Ética dos Profissionais de Enfermagem (Cepe) faz um rol de responsabilidades dos profissionais dessa área, incluindo a obrigação de assegurar à clientela uma assistência segura, isenta de riscos ou de prejuízos decorrentes de negligência, imperícia ou imprudência (artigos 12 e 21 do Cepe) ${ }^{(2)}$. O profissional consciente e responsável deve avaliar criteriosamente sua competência técnica, científica, ética e legal e somente aceitar encargos ou atribuições quando capaz de ter desempenho seguro para si e para outrem (artigo 13 do Cepe). Assim, para uma tomada de decisão autônoma por parte do profissional de enfermagem, é preciso avaliar, primordialmente, os fundamentos éticos no próprio Código de Ética no que tange a responsabilidades, direitos e deveres.

O Código de Ética dos Profissionais de Enfermagem leva em consideração a necessidade e o direito de assistência em enfermagem da população e os interesses do profissional e de sua organização. Está centrado na pessoa, na família e na coletividade e pressupõe que os trabalhadores de enfermagem estejam aliados aos usuários na luta por uma assistência sem riscos nem danos e acessível a toda a população (preâmbulo do Cepe, 2007)(2).

O aprimoramento do comportamento ético do profissional passa pelo processo de construção de uma consciência individual e coletiva e pelo compromisso social e profissional, configurado pela responsabilidade no plano das relações de trabalho com reflexos no campo científico e político ${ }^{(2)}$.

$O$ agir ético profissional deve prevenir prejuízos ao paciente devido à falta de atenção, negligência ou mesmo imperícia. Acredito que essa seja uma importante razão por que o Cepe 2007 tem enfatizado o dever de prevenção de riscos de ocorrências malévolas ao paciente, embora a conduta do profissional não se revista da intencionalidade de provocar a exposição do paciente a situações de perigo ou danos de qualquer natureza. Assim, o agir culposo, ou seja, sem a intenção de causar dano a outrem, pode resultar em algum tipo de risco ou dano ao paciente quando comprovada a negligência, imperícia ou imprudência do profissional.

O agir culposo caracteriza-se pela ausência de intencionalidade daquele que é responsável pela lesão a outrem, pois não almeja o resultado prejudicial, embora, algumas vezes, assume o risco de causar tal situação, pela 
atitude precipitada ou impulsiva. Assim, a imperícia consiste na incompetência, inexperiência ou inabilidade. Envolve o despreparo prático ou teórico para o exercício profissional(14).

A negligência consiste na inação, omissão ou não fazer algo que deveria ser realizado e que era esperado do profissional por obrigação legal ou contratual. A negligência engloba também a desatenção, o descuidar ou a desídia( ${ }^{(4)}$.

Caracteriza-se como conduta imprudente uma ação impulsiva, precipitada, açodada, ou seja, sem cautela necessária ou sem avaliar as consequências malévolas do agir.

A ação ou inação do profissional abrange aspectos concernentes à culpa profissional $\mathrm{e}$ o indivíduo que age ou deixa de agir (quando era esperado legalmente que o fizesse) poderá ser responsabilizado por sua conduta. Cabe, entretanto, ressaltar outros aspectos relativos

à obrigação do respeito à privacidade e ao sigilo ético nas relações interpessoais como elemento fundamental da atuação profissional.

Nesse sentido, é importante distinguir os seguintes tipos de responsabilidades "concretas", com a responsabilidade entendida na presença do outro, incluindo as relações interpessoais, que envolvem os seguintes aspectos:

- cuidar dos outros, em particular, é deixá-los simplesmente que sejam seres com suas possibilidades mais reais, ajudando-os a crescer, e, com isso, viver na realidade do mundo presente, também se preocupando com os membros das comunidades em que habitam (famílias, comunidades de trabalho, entre outros);

- somos também responsáveis por sustentar nossos modos de lidar com as pessoas, com as coisas e com o mundo, que são constitutivos do lugar em que vivemos, que incluem as descobertas e todo avanço da ciência. A ciência em si acaba por modificar o modo de o homem viver e se relacionar em sociedade e, assim, define nossas obrigações morais e legais ${ }^{(15)}$.

\section{CONSIDERAÇÕES FINAIS}

Dois aspectos são relevantes no que tange à temática dos fundamentos éticos e morais da prática da enfermagem. Assim, entendemos que conceber o ser humano como um valor objetivo é reduzi-lo à condição de coisa ou mercadoria, o que por si já caracterizaria uma conduta eticamente inadmissível. O mesmo ocorre quando o profissional que atua na área da saúde trata o paciente como um objeto, sem cuidar dele como alguém que existe, que tem sua história, vontade, expectativas, desejos. Essa seria uma atitude irresponsável e não ética. É certo que a reciprocidade envolve as relações com o outro

e com o mundo. Também seria sustentada pelos princípios e pelos valores em que se acredita, que incorporam respeito e justiça.

O segundo ponto importante acerca da temática discutida consiste em não limitar a ética a um conjunto de normas, hermeticamente fechadas, prontas e acabadas. Ela pode ser representada por um conjunto de normas que regulam a convivência e o comportamento de pessoas em sociedade. É comum que essas pessoas tenham seu código de ética, de modo a guiar suas ações. Assim, o código de ética de uma categoria profissional específica dificilmente contempla todas as situações ou vicissitudes, mas procura orientar profissionais sobre comportamentos deles esperados nas relações com o cliente e com os colegas e outros profissionais no que tange às circunstâncias em que deve manter sigilo, por exemplo, sobre um fato que tomou conhecimento em função do exercício profissional.

\section{Referências}

1. Boff L. Ética e moral: a busca dos fundamentos. Petrópolis: Vozes; 2003.

2. Conselho Federal de Enfermagem. Resolução 311/2007. Aprova o Código

de Ética dos Profissionais de Enfermagem [Internet]. [citado em 2008 Out 8].

Disponivel em: http://corensp.org.br/072005/.

3. Reale M. Liçōes preliminares de direito. São Paulo: Saraiva; 1995.

4. Fernandes MFPF, Freitas GF. Fundamentos da ética. In: Ética e bioética: desafios

para a enfermagem e a saúde. São Paulo: Manole; 2006.

5. Murachco HG. Algumas consideraçōes sobre a ética de Aristóteles: o homem na

pólis e nas relaçōes individuais. Hypnose. 1997;2(3):30-7.

6. Rios T. Ética e utopia. In: Martini A. O humano, lugar do sagrado. São Paulo: Olho

D'Agua; 1995.

7. Vasquez AS. Ética. Rio de Janeiro: Civilização Brasileira; 2003.
8. Segre M, Cohen C. Bioética. São Paulo: Edusp; 2002.

9. Cohen C, Segre M. Definição de valores, moral, eticidade e ética. In: Segre M, Cohen C. Bioética. São Paulo: Edusp; 1995.

10. Chauí M. Convite à filosofia. São Paulo: Ática; 1999.

11. Fernandes MFP. Evolução filosófica da ética. In: Oguisso T, Zoboli E. Ética e

bioética: desafios para a enfermagem e a saúde. São Paulo: Manole; 2006.

12. Goldim JR. O processo de consentimento livre e esclarecido em pesquisa: uma

nova abordagem. Rev Assoc Med Brás. 2003;49(4):372-4.

13. Diniz MH. Curso de direito civil brasileiro. São Paulo: Saraiva; 2006.

14. Oguisso T, Schmidt MJ. O exercício da enfermagem: uma abordagem ético-

legal. Rio de Janeiro: Guanabara Koogan; 2007.

15. Loparic Z. Sobre a responsabilidade. Porto Alegre: EdipucRS; 2003. 